\title{
USING RQDA IN QUALITATIVE DATA ANALYSIS: A TOOL FOR RESEARCHING CHRONIC PELVIC PAIN USING THEMATIC ANALYSIS
}

\author{
Bruna Helena Mellado1, Catarina Brandão ${ }^{2,3}$, Taynara Louisi Pilger ${ }^{1}$, Francisco José \\ Candido dos Reis ${ }^{1}$ \\ ${ }^{1}$ Department of Gynecology and Obstetrics, Ribeirão Preto Medical School, University of São Paulo, Brazil. bru.mell@usp.br \\ taynara.pilger@usp.br; fjcreis@.usp.br \\ ${ }^{2}$ Faculty of Psychology and Educational Sciences of the University of Porto, Portugal. catarina@fpce.up.pt \\ 3 Psychology Center of the University of Porto, Portugal
}

\begin{abstract}
Computer-assisted qualitative data analysis software (CAQDAS) provides tools that help researchers develop qualitative research projects. These software packages support users with tasks such as transcription analysis, text encoding and interpretation, writing and annotation, searching, recursive abstraction, and data mapping, enabling the use of different methods (e.g., grounded theory) and analysis techniques (e.g., content analysis or discourse analysis). The choice of CAQDAS is directly related to the researcher's chosen methodological approach. The amount and variety of software available often makes the choice process difficult. In Brazil, the data on the use of CAQDAS is still scarce. Commercial software packages are more frequently cited. Opensource packages, like RQDA, are less popular. In this chapter, we present our experience with the use of RQDA to analyze the data from a qualitative study on chronic pelvic pain in women.
\end{abstract}

Keywords: Computer-Assisted Qualitative Data Analysis Software, RQDA, Thematic Analysis, Pelvic Pain.

\section{INTRODUCTION}

The field of qualitative research is characterized by different epistemological perspectives and methodological orientations, which often leads to intense academic debate (Ghedin \& Franco, 2008; Merriam, 2007). To optimize the analysis of data derived from qualitative research, software packages, known in the literature as computer-assisted qualitative data analysis software (CAQDAS), have been widely used (Cope, 2014). CAQDAS emerged in the early 1980s and became popular in Europe and the United States, especially after the spread of personal computers in the mid-1990s. The first programs were designed to address specific projects, without a priori marketing purposes. They were installed in large computer terminals, in restricted environments and with little or no user-friendly interface. Researchers needed strong computer skills to use early CAQDAS. This resulted in barriers to access and to carrying out studies that depended on CAQDAS (Johnston, 2006; Kelle, 2007; Richards, 2002). At the same time as a growth in the demand for and use of CAQDAS by users or researchers, there is also a considerable increase in the diversity of software packages available in the market (Costa et al., 2016b). 
A CAQDAS package assists users in different tasks, ranging from writing and annotation to complete data mapping, among other features (Costa et al., 2016a). As in other areas, CAQDAS packages are developed to offer feasible solutions that can meet the needs of the emerging research demands (de Souza et al., 2015). Currently, the market offers more than a dozen of these types of tools. Among the characteristics of CAQDAS-type software that contributed to its dissemination are that it: (1) enables users to deal with high data volume; (2) has features that allow the amount of time needed for coding and analysis to be reduced; and (3) provides the possibility of documenting the analytical process. There are also resources for presentation and visualization of the results obtained as well as the facilitation of the combination of data triangulation and methods. An important factor that has contributed to the expansion of the use of CAQDAS is the increasing demand for reliability in qualitative research. CAQDAS incorporate features that enable researchers to ensure the credibility and reliability of their work (Freitas et al., 2017), making the methodological needs required in qualitative structuring more robust and feasible (Costa \& Minayo, 2018; Ribeiro et al., 2016).

The choice of CAQDAS application is linked to the researcher's methodological approach, but the amount and variety of software available often makes the choice process difficult. Ideally, the researcher should assess the needs of computer support for the specific techniques he or she intends to adopt for data analysis. Nonetheless, it is necessary to consider that all CAQDAS packages require an initial learning time, requiring dedication and possibly financial investment in technical training.

There are also tutorials available on the web that lead users through the software step by step, namely regarding RQDA (Huang, 2016). Except for free software, CAQDAS packages follow the license-based purchasing model, some of which are permanent and some for only a defined time. These variables allow a researcher to choose the license that best suits the demands of his or her job.

In Brazil, the pool of qualitative research using CAQDAS is still scant. However, this scenario is beginning to change, especially given the popularization of the use of computational resources and the internet in the academic environment. Presently, the most popular CAQDAS packages are NVivo ${ }^{\circledR}$ and Atlas.ti® (Lage, 2011). 
The use of RQDA is still scarce, which may be explained by a lack of knowledge of its potentialities.

In a recent review, we found that about $40 \%$ of published qualitative studies on chronic pelvic pain used CAQDAS. Atlas.ti $\AA^{\circledR}$ and NVivo® were most often used (Mellado et al., 2019). Building from the scarcity of studies using RQDA in the academic environment, this chapter describes the functionalities of RQDA software that allow the analysis of qualitative data to be optimized. In this chapter, we seek to answer the following guiding question: How can RQDA software be used to optimize the process of analyzing qualitative data? To illustrate, we show the analysis of a doctoral thesis on qualitative research and chronic pelvic pain in women (Mellado, 2019).

\section{OUR RESEARCH ON CHRONIC PELVIC PAIN}

Before talking about our research on chronic pelvic pain, we present a brief explanation of the definitions of chronic pelvic pain provided by the literature. Pain is generally defined as being an unpleasant sensory and emotional experience associated with actual or potential tissue damage or described in terms of such damage (IASP, 2018). Chronic pelvic pain (CPP) in women is defined as chronic or persistent pain felt in pelvic structures for more than six months with continuous or recurrent pelvic pain, as well as symptoms suggestive of lower, sexual, intestinal, pelvic floor dysfunction or dysfunction gynecology in men and women (Engeler et al., 2020). Worldwide, CPP affects $3.8 \%$ to $24 \%$ of women, most of them at a reproductive age (Latthe et al., 2006). It causes suffering, incapability to work, and serious psychosocial and economic consequences (IASP, 2018). It is also frequently associated with a decrease in the quality of life of women specifically within personal, marital, and family spheres (Romão et al., 2009; Souza et al., 2011).

The successful clinical management of this condition is challenging for healthcare professionals, especially with regard to diagnosis and specific treatment of the primary cause of this chronic condition. However, in addition to the physical-pathological issue itself, a good prognosis for the disease requires affected women to receive mental and emotional support. As a result of their daily suffering, they often end up adopting their own strategies to deal with pain and its possible consequences (Peres \& Lucchetti, 2010). These strategies are known in the literature as coping strategies and an understanding of them designates a substantial influence on the successful management of this debilitating condition (Aziato et al., 2015; Roomaney \& Kagee, 2016). 
Researchers started using qualitative research in the field of pelvic pain in 2013. Women with chronic pelvic pain develop a series of coping mechanisms beginning with the first emergence of symptoms (Aziato et al., 2015; Burbeck \& Willig, 2014; Mellado et al., 2016; Roomaney \& Kagee, 2016; Wong et al., 2016). Understanding these mechanisms is fundamental for planning the multidisciplinary care of women with this condition. Hence, the objective of our research was to understand the coping mechanisms of pain in women with chronic pelvic pain.

A multidisciplinary team carried out the project from March 2016 until March 2017. The project was approved by the Research Ethics Committee of the University Hospital of Ribeirão Preto Medical School, University of São Paulo, and was funded by CAPES (Coordenação de Aperfeiçoamento de Pessoal de Nível Superior - Brazil). Our participants were 66 women assisted at the Endoscopic Gynecology and Pelvic Pain Outpatient Clinic (AGDP). This is a reference center for the care of women with chronic pelvic pain in the Regional Health Division of Ribeirão Preto, located in the northeastern area of the state of São Paulo, Brazil.

We gathered data using face-to-face individual interviews (Brinkmann \& Kvale, 2018). The interviews were audio recorded with an MP3 recorder. They lasted an average of 20 minutes. To mediate the interviews, we used a central question that aimed to access and get closer to the story lived by women, "How do you deal with pain?" Once we transcribed the data, we moved to the analytical exploration of the data using qualitative thematic analysis (Clarke \& Braun, 2014), with the support of the R-based qualitative data analysis (RQDA) software. Next, we present our analytical approach step-by-step, making the use of qualitative thematic analysis explicit with the tools available in RQDA.

\section{THE USE OF RQDA SOFTWARE TO ANALYZE DATA IN OUR PROJECT}

RDQA is an open-source R1 package for qualitative data analysis. The package is free to use and can be modified (BSD license). It works on Windows, Linux/FreeBSD, and Mac OS $X$ platforms. RQDA is an easy-to-use tool to assist in the analysis of textual data. The current version only supports plain text formatted data. All information is stored in an SQLite

\footnotetext{
${ }^{1} \mathrm{R}$ is a computational environment and a programming language that has been progressively specializing in data manipulation, analysis and visualization. It is available for different operating systems: Unix/Linux, Mac, and Windows.
} 
database through the RSQLite R package. It includes several standard features of qualitative computer-assisted data analysis (e.g., coding, retrieving information, and queries). Also, it integrates seamlessly with $\mathrm{R}$, which means that: (a) statistical analysis of coding is possible; and (b) functions for data manipulation and analysis can easily be extended by writing $R$ functions. To some extent, RQDA and $R$ form an integrated platform for quantitative and qualitative data analysis (Huang, 2016).

Despite the scarcity of literature regarding RQDA, it is possible to enumerate several potentialities to this software, presented in Table 1 below. Qualitative research tends to produce large amounts of interview transcripts, field notes, and other documents that, if not well managed, may make analysis lengthy and difficult. In this research, we used RQDA to organize and analyze the data in a more operational, systematic, and effective way. The documents generated from the interview transcriptions were extensive and contained a large diversity of information. The software helped us to replace the traditional method of operationalizing qualitative analysis using scissors, glue, paper, and colored pens to highlight the selected sections. Specifically, the software allowed us to work with data and categories in several ways, using thematic analysis. Next, we present this work according to its different phases.

Table 1. RQDA Potentials (based on Huang, 2016)

\begin{tabular}{ll}
\hline Features & Description \\
\hline Document Type & Import plain text. \\
& Import PDF highlights, which is useful for managing literature content (rjpod \\
dependent). & Support for non-English documents. \\
Edition & Organize files into file categories. \\
& File editing after coding. \\
& Develop document, code, coding, project, file, and memos. \\
& Rename files, codes, code categories, and cases \\
& Write and organize fieldwork journals. \\
& Character level encoding using codes. \\
& Arrange codes into code categories, which is critical to theory building. Encoding \\
& recovery, and easy return to the original file (to ease the segmentation problem). \\
& Conditional recovery is also supported. \\
& File search for keywords with keyword highlighting in the open file. \\
& Search for information about a selected case on the Internet through a pop-up \\
& menu. \\
& Calculate the relationship between two encodings, given the encoding indices. \\
& Get a summary of coding and inter-code relationships. \\
& Perform Boolean operations "and", "or" and "no" for encodings, files or cases. \\
\hline
\end{tabular}




\subsection{The Phases of the Work}

In this section we will describe the different stages of our research, illustrating how we made use of RQDA along the way and since the preliminary stages of our work.

\subsection{The First Contact with the Software}

We adopted RQDA given that one of the team's researchers had had previous experience with it in Europe and the USA. We installed it on the notebook of both main researchers (BHM and FJCR) to share the analysis using a Google Drive folder. Researcher BHM encoded the data, and researcher FJCR was then able to follow and check the coding (see Phase Two: Coding the Data).

Use of a CAQDAS takes place in what Freitas and colleagues designate "the new paradigm of self-learning" (Freitas et al., 2017, p. 100). This is the case with RQDA. Using the software initially required us to consult the manual and watch the web video tutorials (http://rqda.rforge.r- project.org/).

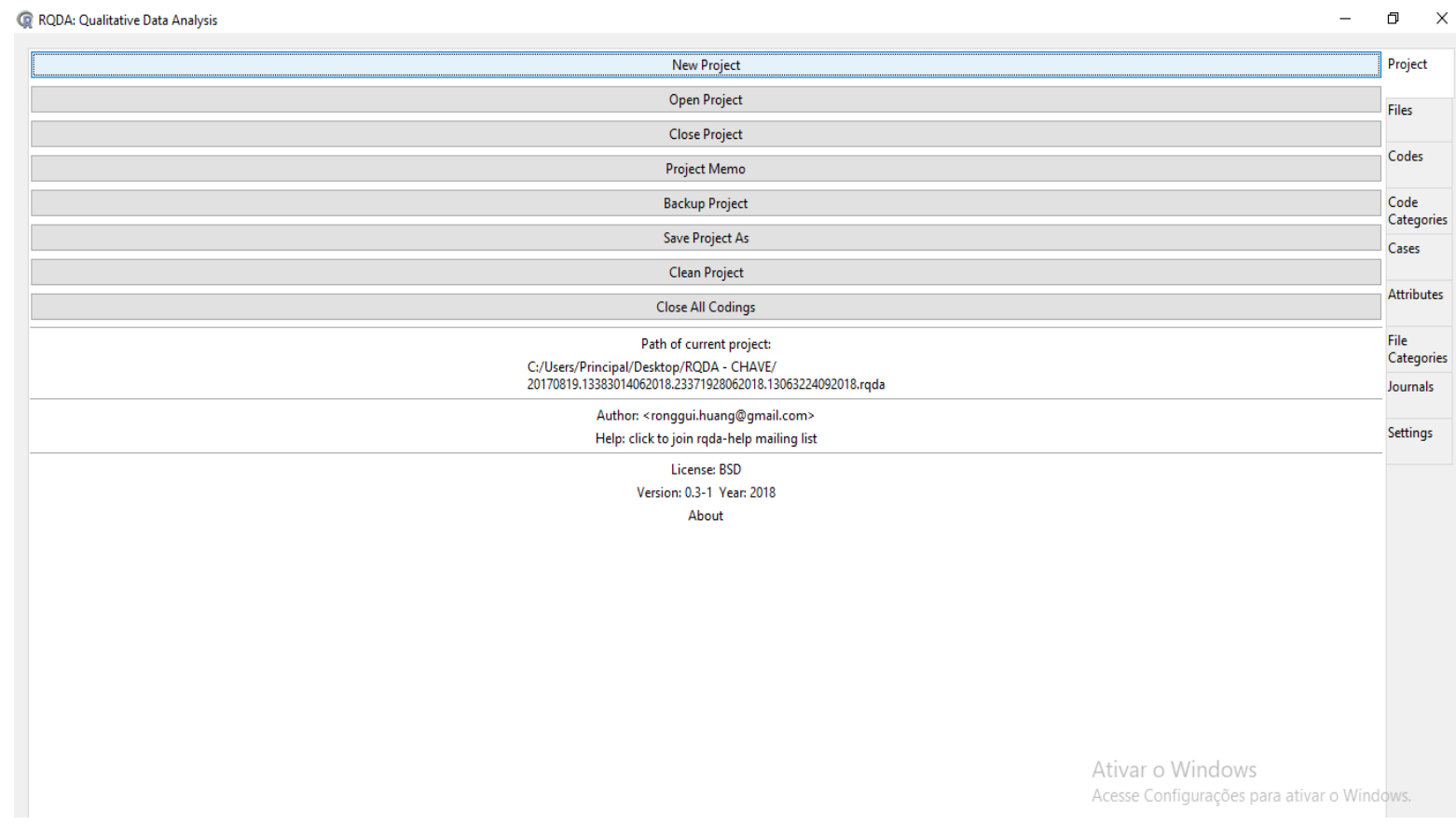

Figure 1.RQDA Software Opening Tab

At that moment, we were not able to find colleagues from the academic area with experience using the software. 
On first impression, RQDA was not very intuitive. The learning process evolved gradually and continuously as we autonomously tried to understand its functionalities. Once familiarized with the way the software worked, we began data processing, a step that preceded the coding and interpretation of the collected data.

\subsection{Phase 1: Preparing the Data}

To start our project, when opening the software, we see the main program tab, as shown by Figure 1 above. To start, we click on "Project"; then "New Project." In order for us to import the data into RQDA, we needed to translate them into *.txt (plain text format) which is an extension available in Microsoft Word.

After transcribing the audio of our interviews in full (which in thematic analysis corresponds to the phase of familiarization with the data), we saved them as plain text using a text editor, one file per interview. We then imported the texts into the new project.

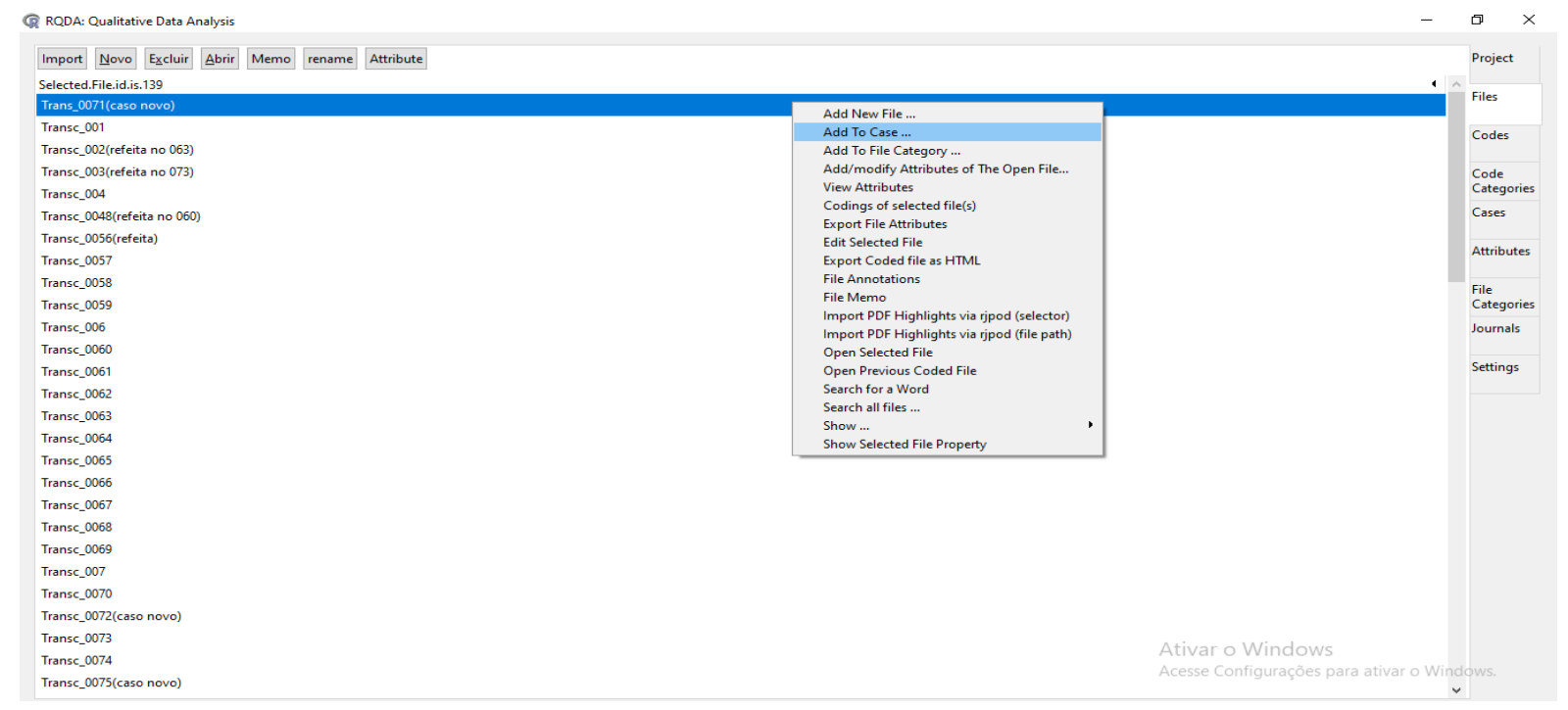

Figure 2. Pop-Up Menu After Clicking "Files" in Figure 1

To import multiple files, we used the R function, typing "File List ()" to import them. When we needed more information, we used "?" and typed "File List." Typing ('?') or '?' is a way to get help to find an object with a non-standard name, such as the help operator? The name should be quoted: for example, help ('?') Or? "?" (https://www.r-project.org/help.html). 
We can also add files by right-clicking the Files folder at the right of the screen (see "Files" in Figure 1) and selecting the intended files from the associated pop-up menu (see Figure 2 above). Here, we can also view specific file encodings, export codes to HTML, and search for a word or file. At top of the pop-up menu, the user finds several options which may be applied to files: Import; Novo (New, in English); Excluir (Exclude); Abrir (Open); Memo; Rename; and Attribute. On the left side of the screen we see the list of files we imported to our project (all of them in plain text format); the user can also click with the mouse and open a tab that allows them to perform other operations, such as adding a new file, adding to the file category, exporting files encoded as HTML, exporting file attributes, file memo, and file annotation, among others as shown below. Finally, on the right there are the options of the prior menu (see Figure 1 above).

Table 2 .Examples of Significant Passages and their Initial Codes

\begin{tabular}{|c|c|}
\hline Initial codes & Data extracts with codes \\
\hline Get used to & $\begin{array}{l}\text { "It's as I told you... I take medicine for the colic, and the pain comes } \\
\text { back... and since it's been a year, I've gotten used to the pain..." }\end{array}$ \\
\hline Lie down & $\begin{array}{l}\text { "It's been about } 20 \text { days since I was in bed, all weekend I was just } \\
\text { lying down ..." }\end{array}$ \\
\hline
\end{tabular}

\subsection{Phase 2: Coding the Data}

In this stage, we created codes or categories and reread the transcribed material with the selection of significant data sections. To begin the coding process itself, it is necessary to have prior knowledge of the data. This typically happens during the process of transcribing the interviews and during the primary reading of the transcribed texts. Thus, we began generating initial codes, phase two of thematic analysis, doing a basic analysis of the collected data. These initial codes represented the central thematic words of each significant passage (see Table 2 above).

We based the process of marking significant passages and assigning them to initial codes on this first reading of the collected data, which translated the first visual contact with the participants' speech. At this moment, we selected 507 significant passages that represented the answer to our research question. We assigned initial codes to all of these passages.

To create these initial codes in RQDA, we used the "Codes" tab (seen on the right side of Figure 2 above), which allowed us to see our data in the project. 
We assigned the new code to the transcript excerpts adopting the following procedure: With the transcript open, we selected the excerpt to be coded, and then the code was chosen in the "Codes" tab. Then we activated the command "Mark," shown in the top left in Figure 3 below. As shown by Figure 3, the user will see the options "Add" and "Delete" on the left side at the header. Below, on the left, there is the list of codes we created for the project. They are: get used to the pain; believe in God; adapt; endure the pain; decrease pain; have support; learn to live with pain; seek a path; keep your head busy; the cause of everything; cry; command life; reconcile the pain; control your head; talk; sew; create ways to deal with pain; give attention to pain; lie down; get stressed; and to depend on others getting things done.

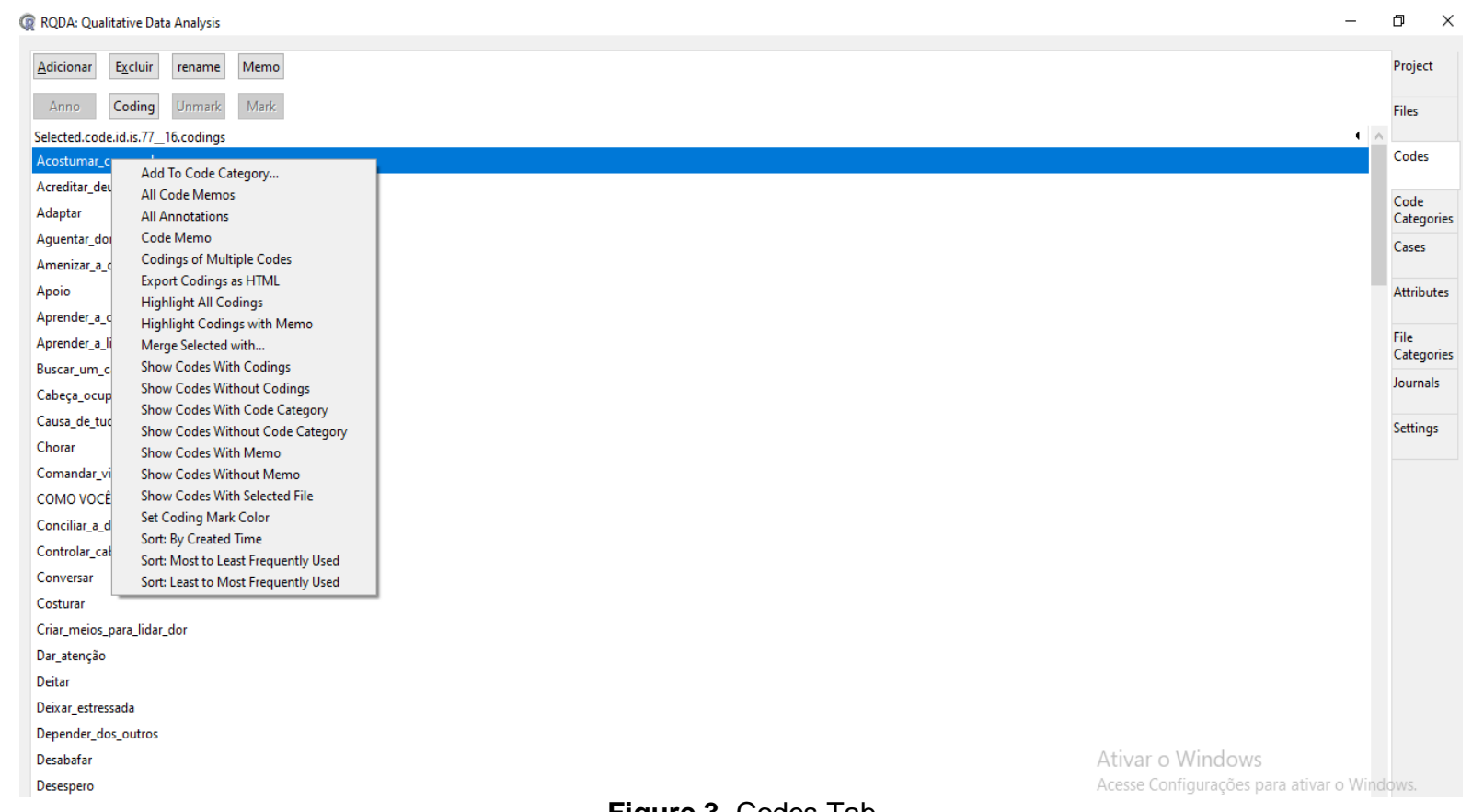

Figure 3. Codes Tab

When conducting the analysis, it was sometimes necessary for us to rename a code, which we operationalized by selecting the code and clicking "Rename." We could also remove a code previously assigned to data by using "Unmark." Both of these options are available in the menu seen at the top left side of Figure 3 above. A fast way to code is to first read the data files and identify possible main codes. A researcher can always add other codes later, but it is best to have an idea of what the researcher wants to code before beginning coding. Codes can be created using the "Codes" tab and "Add." The main point of coding is to apply 
a label to a piece of text. A researcher can choose a word, phrase or several sentences/paragraphs to code. It is good practice to encode some phrases surrounding the relevant word or concept, which will provide context for the information when text fragments or quotations are exported at some point. A researcher can create as many codes as they like, but it is strongly recommended to focus only on the concepts which are relevant to the study.

As mentioned in the "The first contact with the software" section of this chapter, we installed RQDA on the notebooks of two members of the research team. These two members were responsible for the data encoding. Specifically, BHM would code and then FJCR would analyze the coding. When they disagreed on the analysis, they would go back to the data and reach a consensus. This process is called inter-coder reliability (Miles \& Huberman, 1994).

\subsection{Phase 3: Searching for Themes}

After coding all the data, we searched for themes, which is phase three of thematic analysis. We read and grouped the initial codes with the aim of maintaining a significant relationship between them; that is, the approximation of the verbal content that each code brought with it. To do this in RQDA, we used the "Code Categories" tab, seen at the right side of Figure 4 below. When creating a theme, we used the "Code Categories" tab and inside it we clicked "Add to." When relevant, these themes could be renamed using "Rename," seen at the top left of Figure 4. The user can regroup and change initial themes as excerpts as they are revisited in a recursive process of analysis. For this, we use the tabs "Code Categories" and "Rename." We also made notes on topics using the code category Memo, seen in the popup window in the center left of Figure 4. We marked or unmarked the code category in the text using "Mark" or "Unmark." The "Rename" function appears in the "Code Categories" tab header in addition to other functions such as "Delete," "Mark," "Unmark," "Add to," and "Memories" represented by the acronym Memo, as shown in Figure 4 below.

Different tools may support this phase of searching for themes. Using RQDA, we consulted our initial codes and visual representations. We represented our themes in RQDA using the tool "Code Categories," seen on the right side of Figure 4, similarly to how we created our initial codes. We looked at our initial codes, considering the information or excerpts encoded, and then combined them into code categories (themes), identifying a tentative relationship 
between them. To do this we right-clicked on "Code Categories" and, in the options menu, "Selected Category Encoding."

This showed us the encodings of the selected initial code. We could add a new code category to represent a theme. We also could add codes to this new category (representing a theme) or remove a code by selecting it and then "Drop from," seen in the top left of Figure 4. In addition, to see all encoded texts (segments) under a specific code, we double-clicked on it.

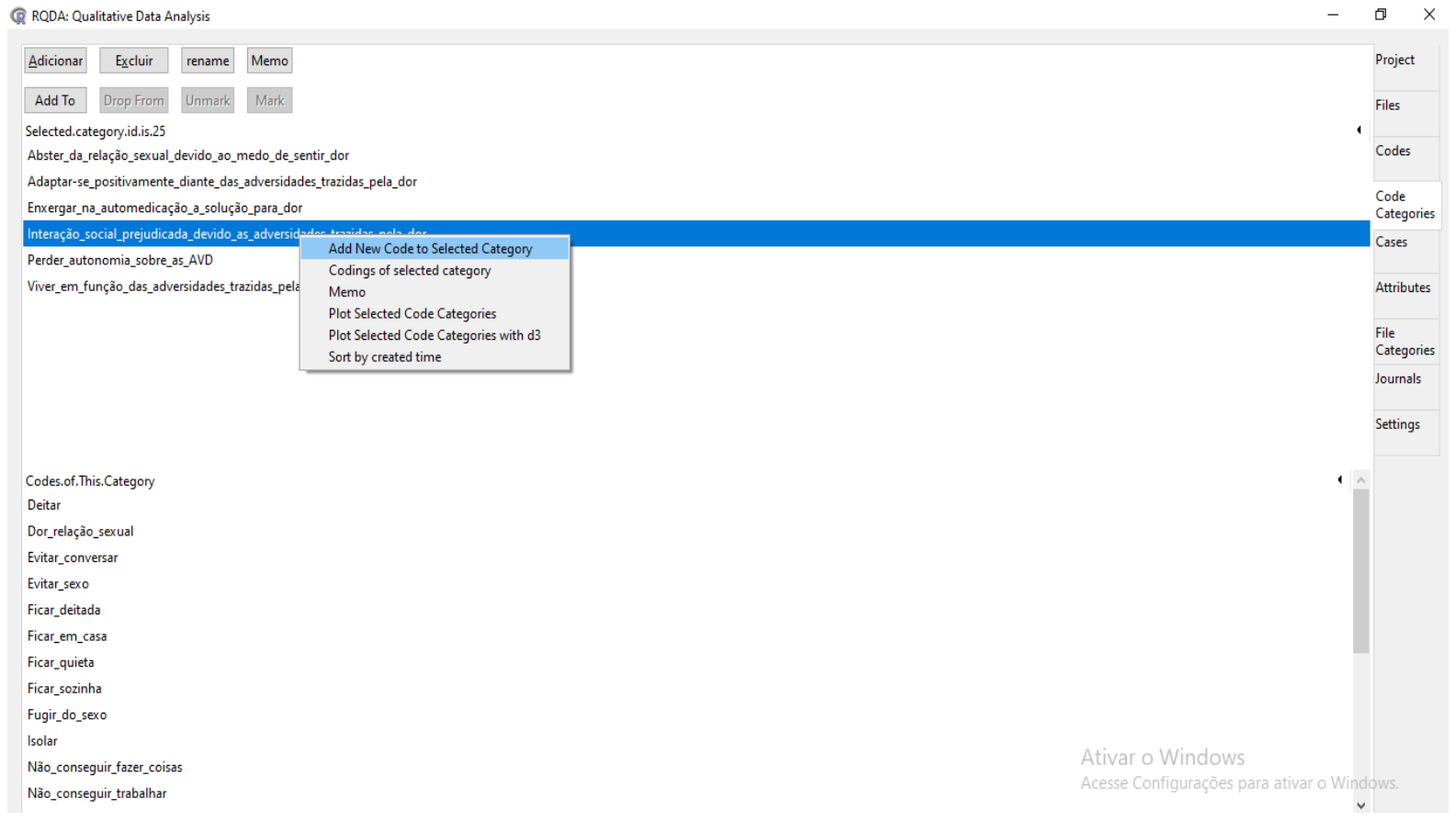

Figure 4.Active "Code Categories" Tab

Code categories are flexible. RQDA allows an initial code to be classified into any number of code categories as needed. They are a way of organizing a researcher's ideas, helping them understand the relationships between codes, and retrieving specific coded texts that support the researcher's analytic hypothesis. Document sizes generated by the software will vary according to the number of data segments coded.

After completing the phase of searching for new themes or thematic renaming, all documents should be reread and reanalyzed, to keep the primary and subsequent analyses in line. This will improve the analysis. 


\subsection{Visualizing categories and codes in an integrated way}

As mentioned above, we also used visual representations. Figure 5 below, for example, supported us in understanding how different codes could be sorted into a specific theme. To build this visualization we used the tab "Code Categories," seen on the right side of Figure 4 above.

We then selected the code referring to "Social_interaction_due_to adversities_associated to pain," selected at the left side of Figure 5.

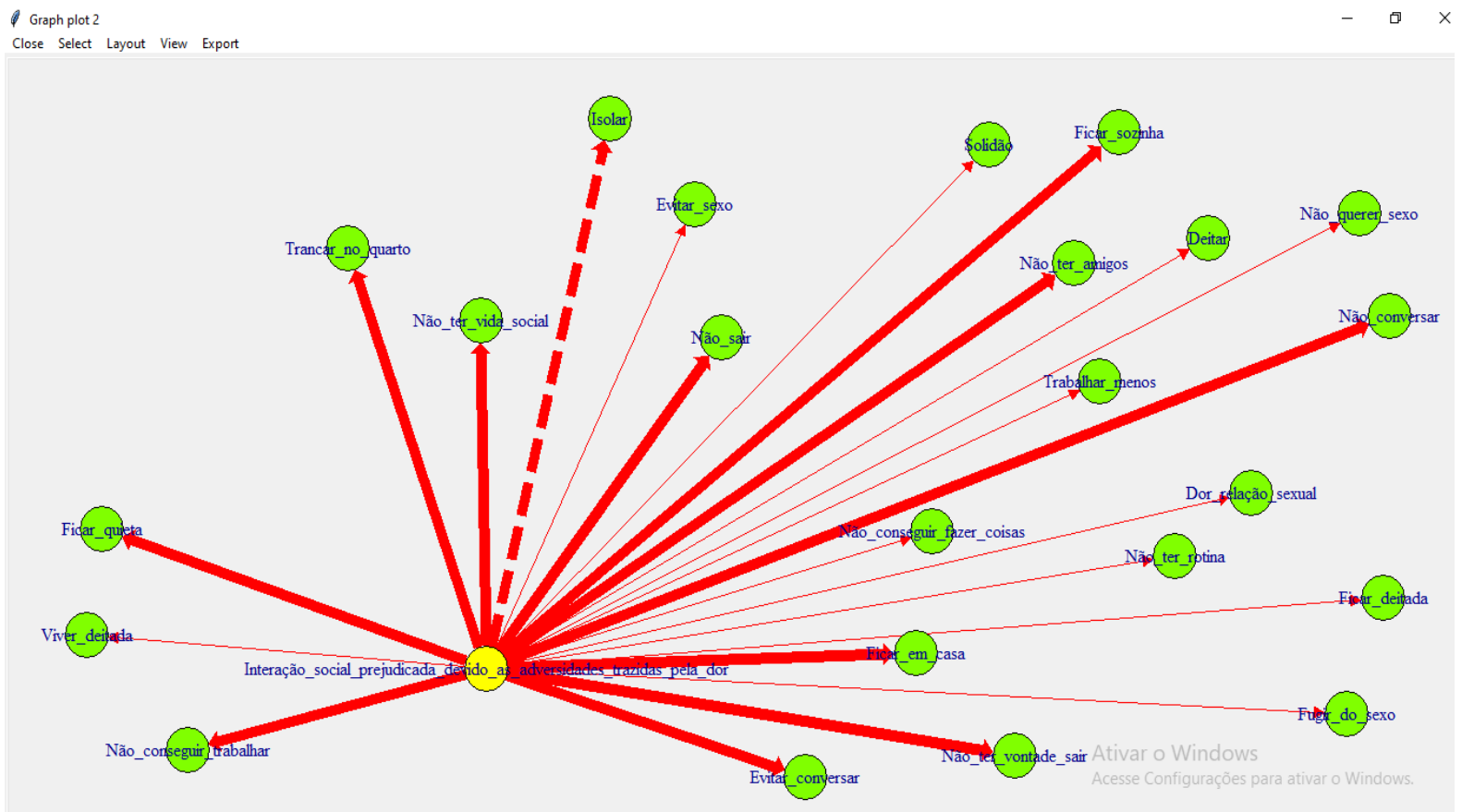

Figure 5. Codes Associated with a Specific Theme in Our Study

Next, we left-clicked to open a pop-up box. We then selected "Plot Selected Code Categories," an option also visible in Figure 4. This selection took us to the screen "Graph Plot," presented in Figure 5.

This type of visualization allowed us to optimize and compile all the codes that allude to a theme. Visualizations are important for compiling information, representing large data in a single figure.

Visualization also support the researcher in the process of interpreting the data and communicating it to an audience. For us specifically, it helped us understand the raw data 
and reflect on the whole process until its final synthesis. It also helped us understand the path we had taken along the data analysis process.

A researcher can also create a basic code view scheme within a category in RQDA by rightclicking on the code category and selecting "Plot Categories Selected Code," an option seen in Figure 6 below. Visualizations may also be exported, using the tab where they were plotted, using the option "Export."

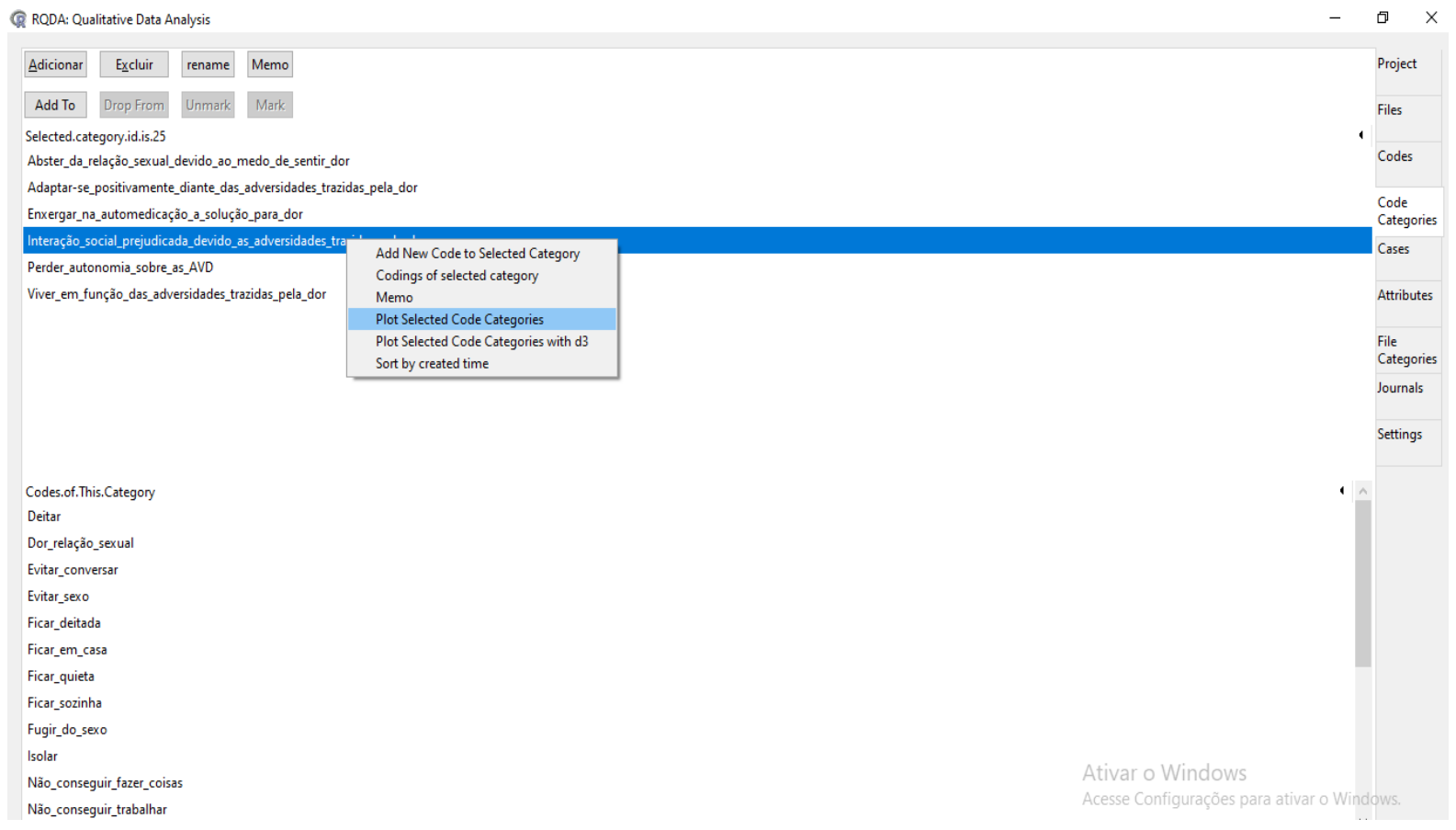

Figure 6.Code Categories Associated with Tab "Plot Selected Code Categories" in Our Study

Data analysis can also be performed using other $\mathrm{R}$ functions, such as $\mathrm{R}$ Commands (Studio) and RQDA Plus. R (Studio) is a good way to get quick summaries of your encodings; for example, the total number of codes, the number of quotations/text segments per code, the number of cases, etc. However, it is not as useful for analyzing color or to read snippets of certain codes. RQDA Plus allows the program to launch an application window to help perform more complicated data analysis in a few steps. It does not conduct easy-to-perform analyses with the RQDA GUI or online R commands.

Through the GUI, RQDA can: import documents from plain text or on the fly; import PDF highlights (useful for content management of literature, reliant upon rjpod); support nonEnglish documents (Simplified Chines Character is well-tested under Windows as well as 
Debian Linux (with locale of zh_CN.UTF-8); character-level code using codes; file edit after coding; memo documents, codes, coding, project, files and more; retrieve coding, and easily return to the original file (to ease the problem of segmentation) and conditionally retrieve; use a single-file ( ${ }^{*}$.rqda) format, which is basically a SQLite database; store data in UTF-8, making it portable; organize codes into code categories, which is key to theory building; organize files into file categories; search files by keywords with highlighting of the keyword in the open file; apply attributes to file, which is useful for content analysis; use a case category and related attributes of cases, which is a crucial feature in bridging qualitative and quantitative research; search information about a selected case on the Internet via a pop-up menu; temporarily delete files and codes; rename files, codes, code categories, and cases; and write and organize field work journals (Huang, 2016).

Table 3. Tools for Operationalizing Qualitative Thematic Analysis in RQDA

\begin{tabular}{ll}
\hline Concepts in Qualitative Thematic Analysis & Useful Tools in RQDA \\
\hline Data familiarization & Files \\
Initial codes & Codes \\
Themes & Codes \\
Theme review & Codes or Code categories \\
Naming of themes & Codes or Code categories \\
Collating codes & Code categories \\
Thematic map & Code categories (Plot selected tab) \\
Data extract & Files or Codes or Code categories or Cases (Export tab) \\
\hline
\end{tabular}

\subsection{Phase 4: Identifying Our Thematic Map}

The phase of searching for themes then evolved to phase four of qualitative thematic analysis, reviewing themes. We consulted our candidate themes, deleting or collapsing these when we considered it appropriate. We also re-read data segments coded at several levels. We then produced some visualizations that helped us represent our results and, hence, the data associated with our research objectives. Despite RQDA having visualization tools, we felt these were not sufficient and moved to using other software, such as Microsoft PowerPoint, in order to produce more informative visualization that we thought best represented the experience of the participants in our research. We believe this signals an opportunity for improvement in the software. Table 3 above presents some of the different tools available in RQDA that we used during this research project, in order to operationalize qualitative thematic analysis. This table serves as a help tool for researchers who wish to use this software to conduct qualitative thematic analysis. 


\section{FINAL CONSIDERATIONS}

CAQDAS has optimized and facilitated the work of qualitative researchers. With the development of software for qualitative analysis, our analytical process became more structured and reliable. There is a growing use of qualitative methodologies in the humanities and in health research, with researchers focusing on diverse themes employing qualitative or mixed research designs. Thus, the quantity and quality of data generated by qualitative research have long been demanding resources that can optimize the work of researchers, to the detriment of the old manual and traditional method of performing the analytical steps in qualitative research.

Based on our experience using RQDA, we recommend it particularly for research using thematic analysis. It is free software, distributed under General Public License (http://www.fsf.org/en_home.html) and it can be installed on multiple computers, thus facilitating teamwork. This contrasts with commercial packages that have highly restrictive licenses and do not allow copies of the software to be installed on more than one computer without proper licensing.

Being open-source allows the creation of new features by advanced users. It is available for many platforms including Unix, Linux, Macintosh and Windows. It is extremely flexible and can be integrated with several other $\mathrm{R}$ platform packages. Yet, RQDA software also has limitations. Not being cloud-based, access is restricted to environments where the software is installed. This limits teamwork and can make the coding verification or inter-agreement process more time-consuming. RQDA also requires basic knowledge of working in an $\mathrm{R}$ environment. Regarding the graphical interface, the tabs are not self-explanatory, which requires time for learning to handle them properly. Given the potential of visualizations tools, RQDA could offer users more visualization tools, as these are central to the research process.

RQDA, like any other CAQDAS, does not replace the need for researchers to analyze the data or to be constantly close to it. As Freitas and colleagues stated, no CAQDAS "will replace the analytical competence of researchers" (Freitas et al., 2017, p. 102). But, overall, RQDA is user-friendly even for beginners. When we combine this with the fact that it is a free software and that most users learn a specific CAQDAS autonomously for their own research project (Costa et al., 2016a), we can see the potential of this software particularly, but not 
only, for novice researchers. We hope that it continues to develop, as this may help support a more democratic access of researchers to researching tools.

Acknowledgements. We would like to thank the Coordenação de Aperfeiçoamento de Pessoal de Nível Superior (CAPES)- Programa de Excelência Acadêmica (PROEX) - Brazil for Financial Support. F. J. Candido dos Reis (grant number 303210/2018-4) was funded by the National Council for Scientific and Technological Development (CNPq). B. H. Mellado (grant number 23038.000832/201831) was funded by the Coordenação de Aperfeiçoamento de Pessoal de Nível Superior (CAPES). T. L. Pilger (grant number PIBIC/USP/2016-413) was funded by the National Council for Scientific and Technological Development (CNPq).

\section{REFERENCES}

Aziato, L., Dedey, F., \& Clegg-Lamptey, J. N. A. (2015). Dysmenorrhea management and coping among students in Ghana: A qualitative exploration. Journal of Pediatric and Adolescent Gynecology, 28(3), 163-169. https://doi.org/10.1016/j.jpag.2014.07.002

Brinkmann, S., \& Kvale, S. (2018). Doing interviews (2nd ed.). SAGE.

Burbeck, R., \& Willig, C. (2014). The personal experience of dysmenorrhea: An interpretative phenomenological analysis. Journal of Health Psychology, 19, 1334-1344. https://doi.org/10.1177/1359105313490313

Clarke, V., \& Braun, V. (2014). Thematic analysis. In A. C. Michalos (Org.), Encyclopedia of quality of life and well-being research (pp. 6626-6628). Springer Netherlands. https://www.ncbi.nlm.nih.gov/pmc/articles/PMC5902253/

Cope, D. G. (2014). Computer-assisted qualitative data analysis software. Oncology Nursing Forum, 41(3), 322323. https://doi.org/10.1188/14.ONF.322-323

Costa, A., Faria, B., \& Reis, L. (2016a). Investigação qualitativa através da utilização de software: Workflows metodológicos [Qualitative research using software: Methodological workflows]. RISTI - Revista Ibérica de Sistemas e Tecnologias de Informação, 1(19), 9-12. http://www.scielo.mec.pt/scielo.php?pid=S1646$98952016000300001 \&$ script=sci_arttext\&tIng=es

Costa, A. P., Souza, D. de, \& Souza, F. de. (2016b). Trabalho colaborativo na investigação qualitativa através das tecnologias [Collaborative work in qualitative research through technologies]. Investigação qualitativa: inovação, dilemas e desafios, 1, 105-127. https://www.ludomedia.pt/en/

Costa, A. P., \& Minayo, M. C. de S. (2018, May 30-June 1). O que Podemos Esperar da Análise de Dados Qualitativos Suportados por Software? [What can we expect from the analysis of qualitative data supported by software?] [Conference paper]. 5th International Seminar on Research and Qualitative Studies, São Paulo.

https://www.researchgate.net/profile/Antonio_Costa18/publication/325646000_O_que_podemos_espera r_da_analise_de_dados_qualitativos_suportada_por_software/links/5b1a633145851587f29caad9/Oque-podemos-esperar-da-analise-de-dados-qualitativos-suportada-por-software.pdf

de Souza, D. N., Costa, A. P., \& de Souza, F. N. (2015). Desafio e inovação do estudo de caso com apoio das tecnologias [Challenge and innovation of the case study supported by technologies]. In N. F. de Souza, D. N. de Souza, \& A. P. Costa (Eds.), Investigação qualitativa. inovação, dilemas e desafios [Qualitative research: Innovation, dilemmas and challenges] (pp. 143-162). Ludomedia, Oliveira de Azeméis, Aveiro.

Engeler D., Baranowski A. P., Berghmans B., Borovicka J., Cottrell, A. M., Elneil P. S., Hughes J., Messelink, E., \& de C Williams A. C. (2020). EAU guidelines on chronic pelvic pain. European Association of Urology. https://uroweb.org/guideline/chronic-pelvic-pain/ 
Freitas, F., Ribeiro, J., Brandão, C., Reis, L. P., de Souza, F. N., \& Costa, A. P. (2017). Learn for yourself: The self-learning tools for qualitative analysis software packages. Digital Education Review, 32, 97-117. https://files.eric.ed.gov/fulltext/EJ1166487.pdf

Ghedin, E., \& Franco, M. A. S. (2008). Questões de método na construção da pesquisa em educação [Issues of method in the construction of research in education] (2nd ed.). Cortez Publisher.

Huang, R. (2016). RQDA: R-based qualitative data analysis. R package version 0.2-8. [R]. http://rqda.r-forge.rproject.org/ (Original work published 2015).

International Association for the Study of Pain (IASP). (2017). IASP terminology. https://www.iasppain.org/terminology?navltemNumber=576\#Pain

Johnston, L. (2006). Software and method: Reflections on teaching and using QSR NVivo in doctoral research. International Journal of Social Research Methodology, 9(5), 379-391. https://doi.org/10.1080/13645570600659433

Kelle, U. (2007). Análise com auxílio de computador: codificação e indexação [Computer aided analysis: coding and indexing]. In M. W. Bauer \& G. Gaskell, Pesquisa qualitativa com texto, imagem e som: um manual prático [Qualitative research with text, image and sound: a practical manual] (pp. 393-415). Petrópolis: Vozes.

Lage, M. C. (2011). Utilização do software NVivo em pesquisa qualitativa: Uma experiência em EaD [The use of NVivo software in qualitative research: An experience in distance education]. ETD: Digital Thematic Education, 12(2011), 198-226. https://doi.org/10.20396/etd.v12i0.1210

Latthe, P., Latthe, M., Say, L., Gulmezoglu, M., \& Khan, K. S. (2006). WHO systematic review of prevalence of chronic pelvic pain: a neglected reproductive health morbidity. BMC PUBLIC Health, 6(177), 1-7. https://doi.org/ 10.1186/1471-2458-6-177

Mellado, B. H. (2019). Análise qualitativa dos mecanismos de enfrentamento da dor em mulheres com dor pélvica crônica [Qualitative analysis of pain coping mechanisms in women with chronic pelvic pain] [Unpublished doctoral dissertation]. São Paulo, Ribeirão Preto.

Mellado, B. H., Falcone, A. C. M., Poli-Neto, O. B., Rosa E Silva, J. C., Nogueira, A. A., \& Candido-Dos-Reis, F. J. (2016). Social isolation in women with endometriosis and chronic pelvic pain. International Journal of Gynecology and Obstetrics, 133(2), 199-201. https://doi.org/10.1016/j.ijgo.2015.08.024

Mellado, B. H., Pilger, T. L., Poli-Neto, O. B., Rosa E Silva, J. C., Nogueira, A. A., \& dos Reis, F. J. C. (2019). Current usage of qualitative research in female pelvic pain: A systematic review. Archives of Gynecology and Obstetrics, 300(3), 495-501. https://doi.org/10.1007/s00404-019-05212-x

Merriam, S. B. (2007). Qualitative research and case study applications in education: Revised and expanded from case study research in education (2nd ed.). Jossey-Bass.

Miles, M. B., \& Huberman, A. M. (1994). Qualitative data analysis: An expanded sourcebook (2nd ed.). SAGE.

Peres, M. F. P., \& Lucchetti, G. (2010). Coping strategies in chronic pain. Curr Pain Headache Rep, 14(5), 331338. https://doi.org/10.1007/s11916-010-0137-3

Ribeiro, J., Brandão, C., \& Costa, A. P. (2016). Metodologia de estudo de caso em saúde: Contributos para a sua qualidade [Health case study methodology: Contributions to its quality]. In E. S. Oliveira, N. Barros, \& R. Silva (Eds.), Investigação qualitativa em saúde: Conhecimento e aplicabilidade (1st ed., pp. 143-160). Ludomedia.

Richards, T. (2002). An intellectual history of NUD*IST and NVivo. International Journal of Social Research Methodology, 5(3), 199-214. https://doi.org/10.1080/13645570210146267

Romao, A. P. M. S., Gorayeb, R., Romao, G. S., Poli-Neto, O. B., dos Reis, F. J. C., Rosa-e-Silva, J. C., \& Nogueira, A. A. (2009). High levels of anxiety and depression have a negative effect on quality of life of women with chronic pelvic pain. International Journal of Clinical Practice, 63(5), 707-711. https://doi.org/10.1111/j.1742-1241.2009.02034.x 
Roomaney, R., \& Kagee, A. (2016). Coping strategies employed by women with endometriosis in a public healthcare setting. Journal of Health Psychology, 21(10), 2259-2268. https://doi.org/10.1177/1359105315573447

Souza, P. P., Romao A. S., Rosa-e-Silva, J. C., dos Reis, F. C., Nogueira, A. A., \& Poli-Neto, O. B. (2011). Qualitative research as the basis for a biopsychosocial approach to women with chronic pelvic pain. Journal of Psychosomatic Obstetrics \& Gynecology, 32(4), 165-172. https://doi.org/10.3109/0167482X.2011.607523

Wong, C. L., Ip, W. Y., \& Lam, L. W. (2016). Self-care strategies among Chinese adolescent girls with dysmenorrhea: A qualitative study. Pain Management Nursing, 17(4), 262-271. https://doi.org/10.1016/j.pmn.2016.04.001 